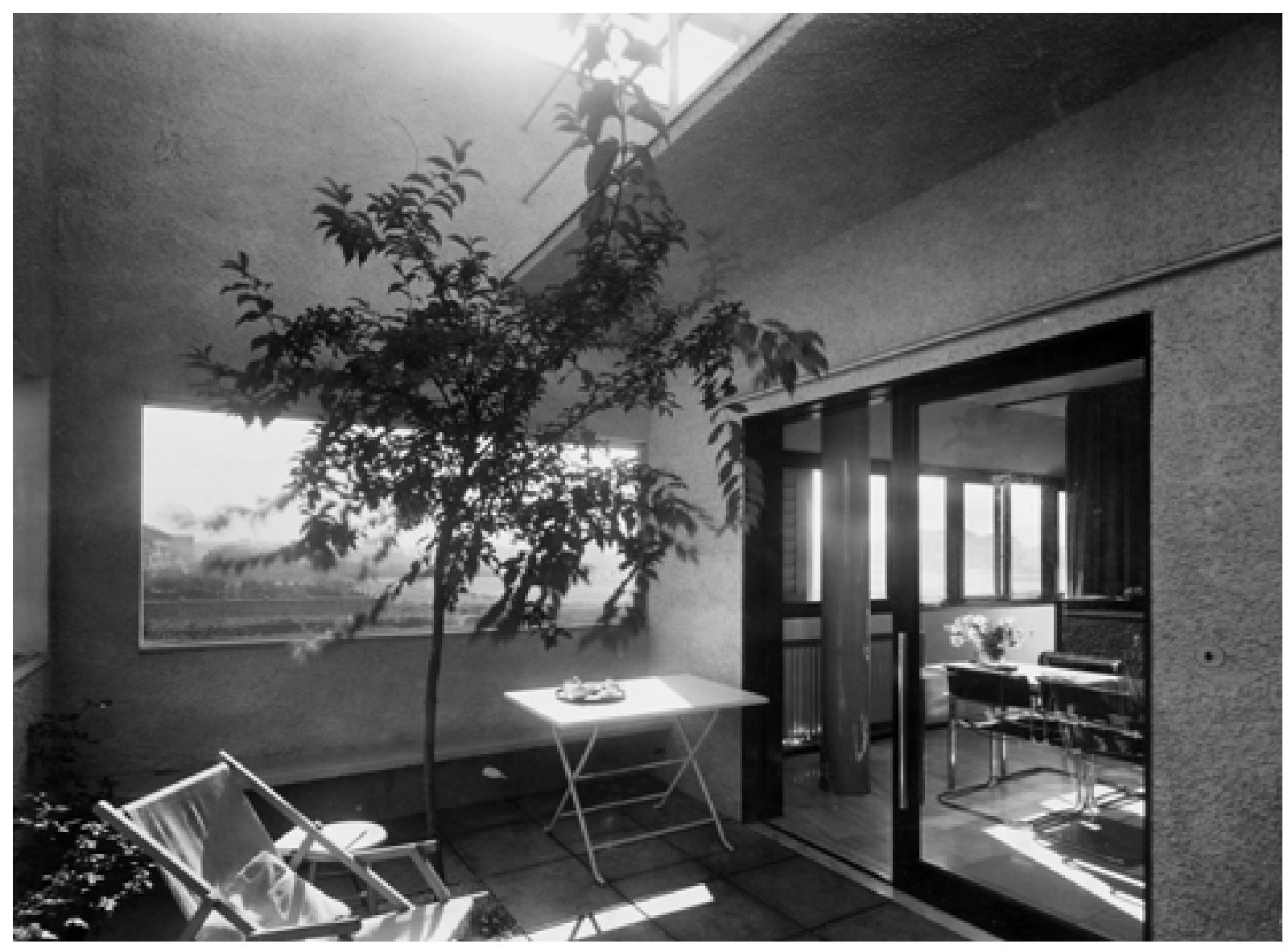




\section{Las terrazas-jardín de la Casa Figini en Milán. Una reconstrucción del paraíso perdido Anna Martínez Fabiola Meignen}

En el libro L'elemento verde e l'abitazione, Luigi Figini recoge su experiencia de vida en las terrazas-jardín de su casa de Milán. La casa se construye en 1935 , el libro se publica en 1950, quince años a lo largo de los cuales el arquitecto recoge y sistematiza, entre las diferentes soluciones para introducir el verde cerca de la vivienda del hombre, la de la terraza-jardín. Conquista de la nueva arquitectura, ésta ha de aportar en la vivienda urbana en altura, el olvidado beneficio del contacto con la madre tierra: con el verde, el cielo, el agua. En estos años, las terrazas se convierten en agradables jardines, y son el fondo de la actividad poética del arquitecto y su esposa. En su casa, Figini reconstruye el Paraíso perdido. La infancia del hombre, la infancia de los tiempos, reencontrada.

PALABRAS CLAVE

Luigi Figini, terraza-jardín, elemento verde, casa del arquitecto

KEYWORDS

Luigi Figini, Terrace-Garden, Green Element, Architect's House

EL ELEMENTO

VERDE Y LA

VIVIENDA
En 1950, tras quince años habitando en la casa del Barrio de los Periodistas de Milán, Luigi Figini publica el libro L'elemento verde e l'abitazione. En el tratado, que edita Domus, el autor recorre, en un discurso poético, la historia del hombre y de la arquitectura, en relación con la naturaleza: el verde, el agua, el sol, el cielo, para finalmente sistematizar las soluciones arquitectónicas para la introducción del verde en la vivienda urbana. En el jardín del Edén, el hombre pisaba la tierra, su techo eran las copas de los árboles, el cielo estrellado. No había estaciones, era la eterna primavera, "la relación entre el hombre y el mundo vegetal había alcanzado la perfección plena: el mundo exterior se identificaba con la casa del

\section{Anna Martínez Durán}

Arquitecto (1989) y Doctora en Proyectos Arquitectónicos por la Universidad Politécnica de Catalunya (2008), con la tesis "La casa del arquitecto". Profesora en la Universidad Politécnica de Cataluña (1991-98) y en la Universidad Ramón Llull (1998 a fecha) en diferentes asignaturas de grado, máster y doctorado, vinculadas a la composición y al proyecto. Desarrolla sus investigaciones en el ámbito del proyecto arquitectónico, en la línea de Investigación de Arquitectura Mediterránea (IAM), grupo Integrated Architectural Research (IAR). Orcid ID 0000-0001-7544-3250

\section{Fabiola Meignen Martínez}

Arquitecto por la Universidad Simón Bolívar de Venezuela (2010), Master en Análisis Estructural de Monumentos y Construcciones Históricas de la Universidad de Minho, Portugal y la Universidad Politécnica de Catalunya (2014). Master en Arquitectura del Paisaje de la Universidad Hochschule Anhalt de Alemania (2016). Actualmente, alumna de Doctorado en la Escuela de Arquitectura de La Salle, Universidad Ramon Llull, en el programa Doctorado Industrial en colaboración con la empresa Mothership, Grupo La Casa por el Tejado, con una tesis doctoral acerca de la implementación del verde en los espacios intermedios de edificios de vivienda plurifamiliar en la ciudad de Barcelona. Desarrolla sus investigaciones en el grupo IAM_IAR (Investigación de Arquitectura Mediterránea), colaborando en proyectos de investigación.

Orcid ID 0000-0003-3403-1246

Fig. 01

Casa Figini en Milán. La sala comedor desde la terraza. 

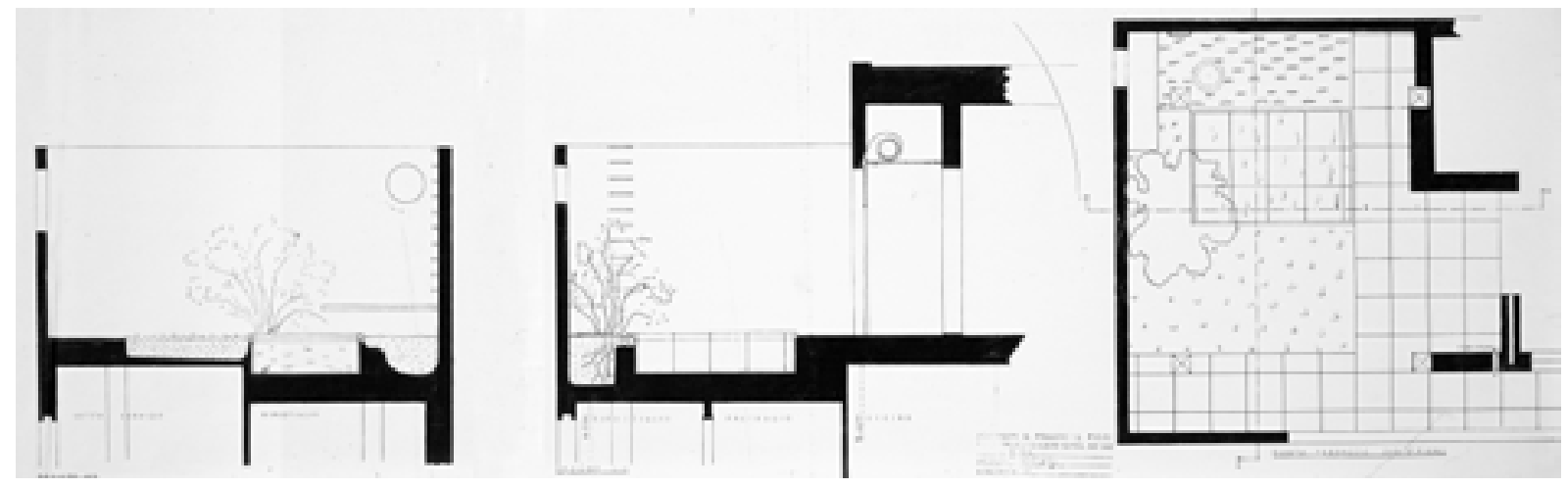

02

hombre, y la casa del hombre con el mundo exterior"1. Sólo después de la culpa aparece la necesidad de abrigo: del clima, de los animales salvajes, de sus semejantes. El hombre construye entonces su refugio con cosas muertas: ramas, troncos, piedra, arcilla. Ha perdido su feliz dominio sobre los elementos. Nace la primera casa, la primera ciudad. Tristes, como el resto de obras del hombre, con la pena del "después de la culpa"2. Desde entonces, la nostalgia de la felicidad perdida, en la infancia del hombre y en la infancia del mundo, acompaña al hombre en su existencia, que intenta reproducir en la tierra, cerca de su hábitat, donde transcurre su vida desierta, una imagen de aquel jardín que vio salir el sol por primera vez. Son la casa pompeyana, el Orto Conclusus medieval, el Riad árabe, el patio de la casa mediterránea popular.

Pero en la ciudad, donde los hombres se apilan unos con otros "estancia a estancia a lo largo de la vertical; allí donde un poco de terreno es suficiente para no sólo una, sino muchas familias, cuando el hombre construye casas de tantos pisos, y acerca estas casas unas a las otras hasta formar una ciudad, entonces el patio histórico muere".3. Para no morir, el patio sólo puede transformarse en la terraza-jardín, conquista de la nueva arquitectura para la vivienda urbana, que retornará a todos los hombres, "un beneficio concreto: el verde; y la ilusión de otro beneficio: el aislamiento, la soledad"4 (fig. 02).

Entre las diferentes imágenes que ilustran el capítulo se presentan terrazas-jardín en todas las geografías, obra de Le Corbusier, Lurçat, Guevrekian, Neutra, Vietti, o Burle Marx, entre otros. Cuatro de ellas corresponden a la casa propia en Milán, diez al ático Beistiegui en París: espacios vacíos, altos muros, sombras profundas, muebles, chimeneas, setos y extensiones de césped, árboles en flor. El interior se instala en el exterior, el exterior invade el espacio interior. 


\section{UN CASA}

SUSPENDIDA EN

EL AIRE, ENTRE

EL CIELO Y LA TIERRA

pilotis. Es el patio romano, el huerto medieval, el jardín árabe, suspendido entre el cielo y la tierra. Luigi Figini, "un hombre lleno de impulsos poéticos y apasionado", construye esta casa en 1934 y residirá en ella junto a su mujer, Gegé Bottinelli, hasta 1984, fecha en la que fallece. Se trata de una obra de juventud, construida como hogar familiar poco antes de contraer matrimonio, en Milán, ciudad natal del arquitecto, donde cursó sus estudios y construyó la mayor parte de su obra ${ }^{6}$, en un barrio residencial con ordenanzas propias de ciudad-jardín. En aquel momento el edificio se hallaba rodeado de algunas viviendas, pero sobre todo de huertos y campos (fig. 03). Esta casa, un prisma blanco, puro, busca manifiestamente el aire y la luz, el calor, en un clima lluvioso y de nieblas como el de la capital lombarda; así como las vistas que, en los días claros, y por el hecho de estar tan alta, eran posibles sobre los montes de Lecco, al Norte, en las estribaciones de los Alpes. Por ello el edificio asienta sobre 12 pilares, dispuestos regularmente en el centro del solar, hasta separarse 4,80 $\mathrm{m}$ del terreno. De esta forma toda la superficie de tierra queda libre, y se destina a jardín y huerto. La ocupación (18x5.5=99 m²) es de exactamente $1 / 3$ parte del total de un solar que, en la actualidad, se ha convertido en un jardín verde y salvaje.
Fig. 02

La terraza-jardín en planta superior.

Fig. 03

Luigi Figini y Gegé Bottinelli en la Villa.

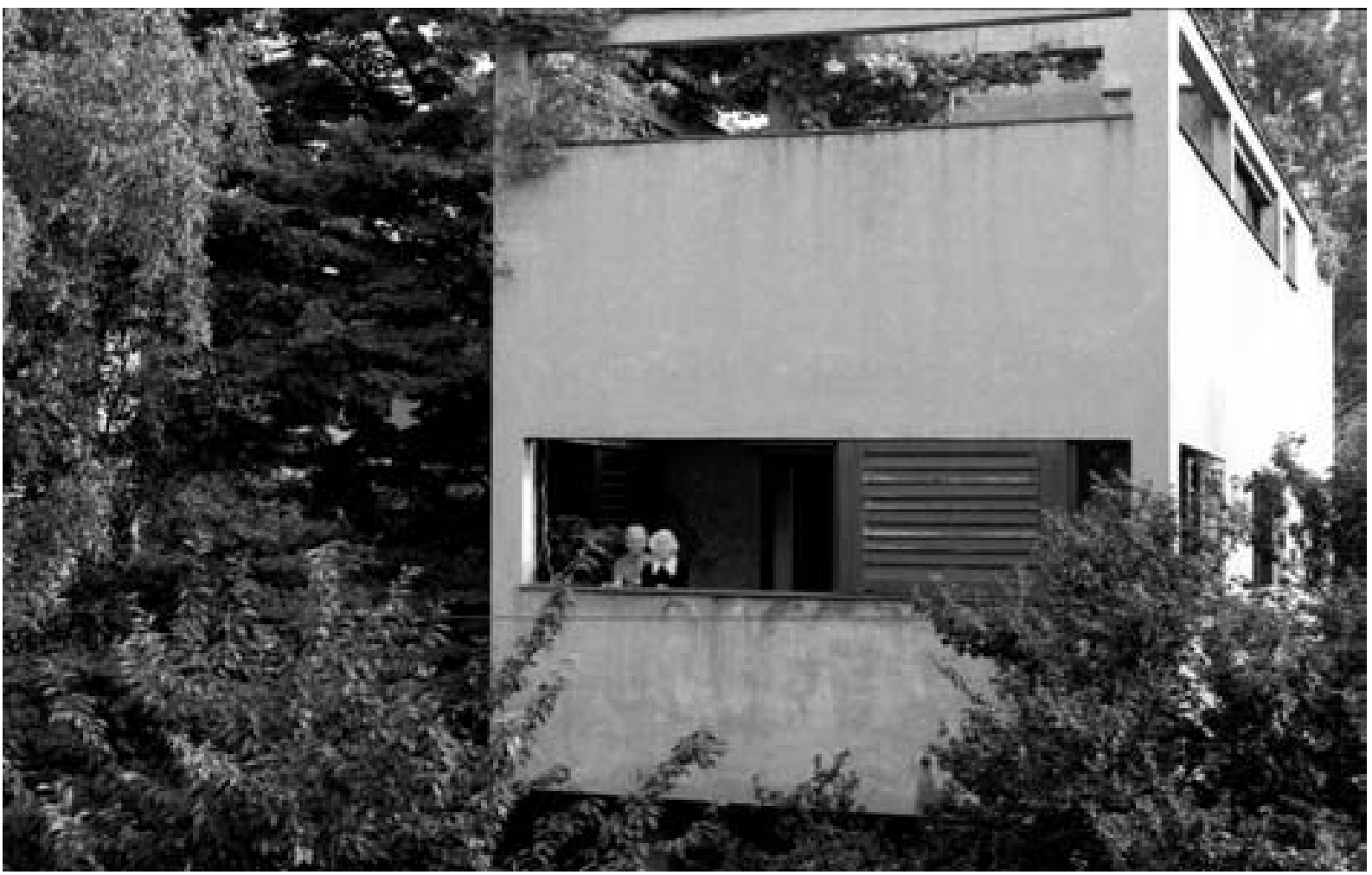




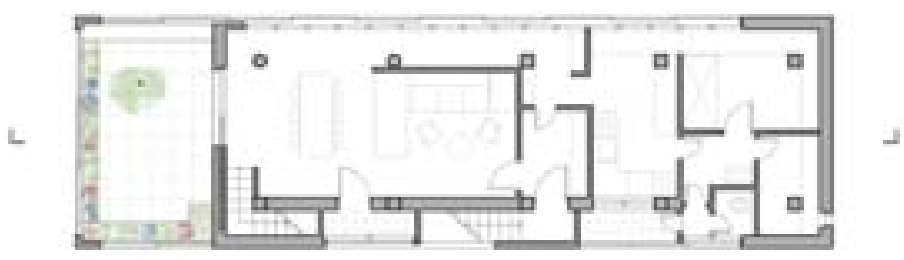

Nivel 1

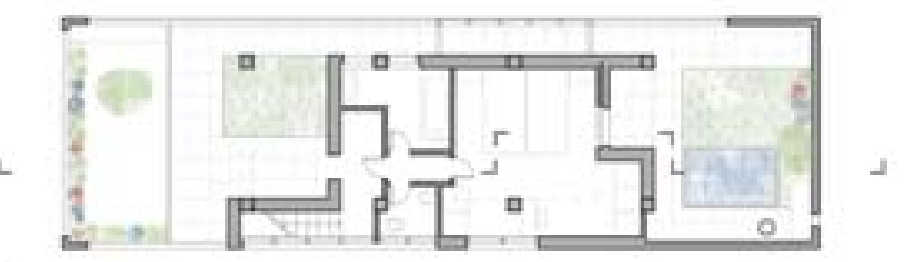

Nivel 2

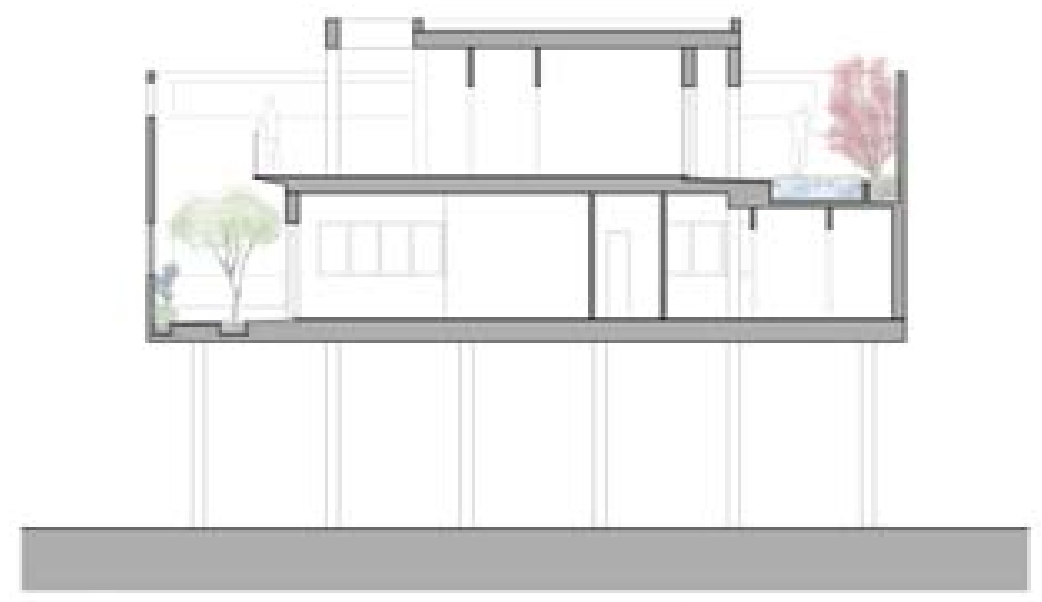

Sección

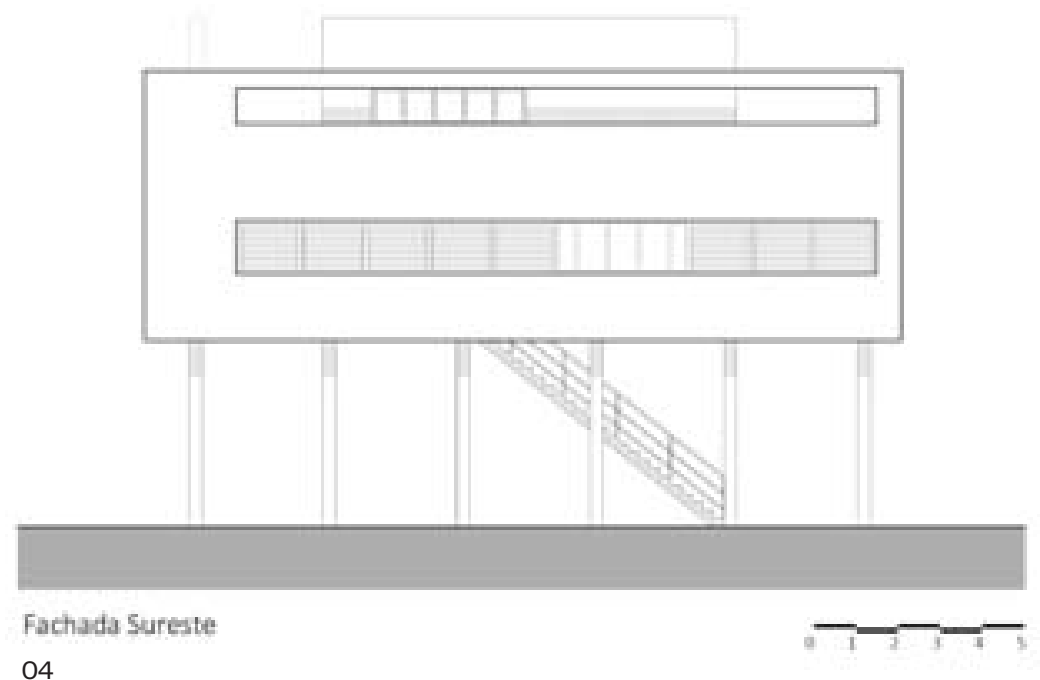


Fig. 04

El elemento verde y la casa.

Fig. 05

La sala-comedor desde la terraza.

La orientación de la casa es prácticamente Norte-Sur, con acceso desde Via Perrone San Martino al NE. El programa se dispone en dos plantas, con la estructura regular de pilares de hormigón retrasada de fachada, y ventanas horizontales corridas en las cuatro fachadas. Una escalera exterior de un tramo estrecha y empinada nos conduce, entre la fachada y la línea de pilares, directamente al centro de la planta principal. A un lado el espacio único del salón-comedor, abierto sobre la terraza, y al otro, las habitaciones de servicio. En el nivel superior se dispone una única habitación con baño y vestidor en el centro, el resto lo ocupan las terrazas y el vacío sobre la planta inferior. La altura de las dos plantas es mayor que la del prisma blanco, por lo que el cuerpo de habitación superior se retrasa en tres de las fachadas, menos en la NO, donde se encaja a una altura menor (fig. 04).

La casa es precisa y rotunda en el planteamiento. El prisma, la estructura y los huecos se proporcionan con ligeros ajustes sobre cuadrados y proporciones áureas. Exteriormente se muestra austera, casi desnuda; preciosa en sus interiores, resueltos con lujo y refinamiento. Suelos de mármol, carpinterías de acero, y en el salón, pilares redondos brillantes, el aparador sobre patas metálicas de la Villa Studio, y sillones de piel de vaca, también diseño del mismo arquitecto. Muy pocos objetos escogidos a la vista: algunas macetas con plantas, y la escultura del "Guerrero decapitado", regalo de Fausto Melotti al matrimonio Figini (fig. 05).

LAS TERRAZAS-JARDÍN

En esta casa, las terrazas-jardín, ocupan casi tanta superficie como los interiores. Se disponen en las dos plantas y en todas las orientaciones, con diferentes usos y caracteres. En ellas son muy pocos los elementos artificiales -la obra del hombre- frente a los elementos de la naturaleza: verde, agua, arena y cielo. Encerradas entre muros, para que el individuo pueda presentarse, en soledad, en coloquio consigo mismo y con el Creador. En la terraza de la planta princi- 
Fig. 06

Gegé Bottinelli y Luigi Figini en la terraza

de la sala.

Fig. 07

Las terrazas de la planta superior.
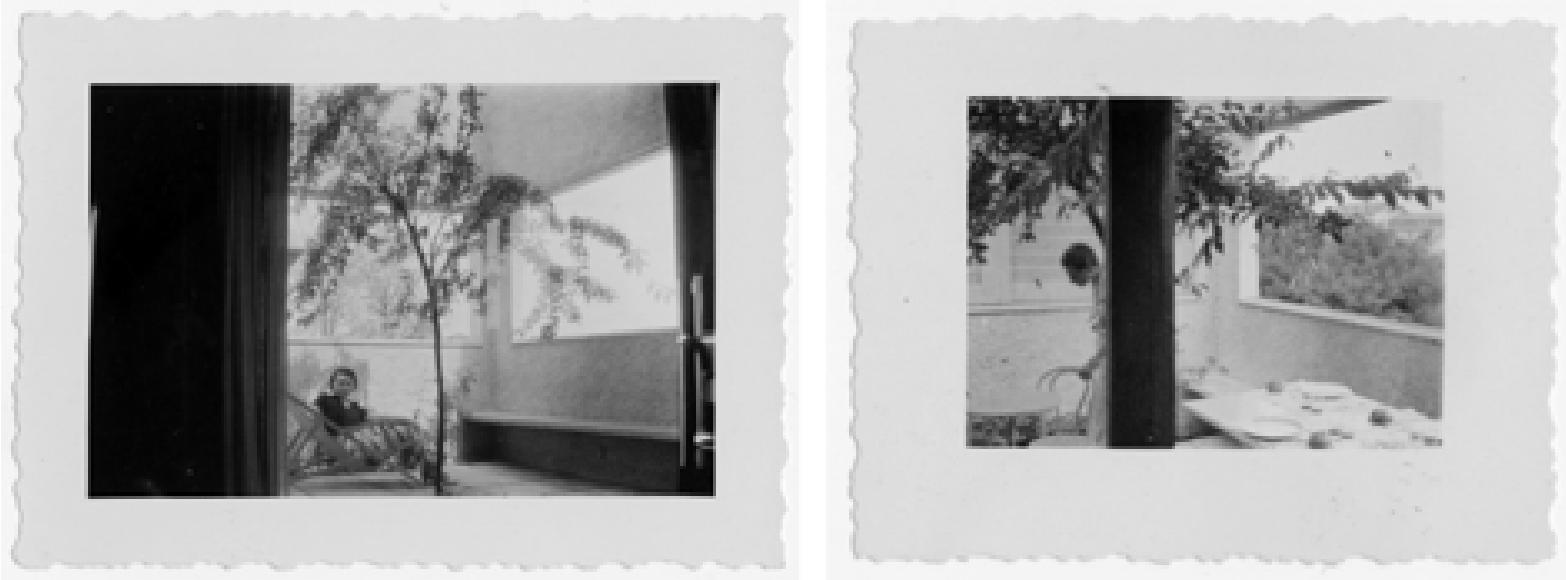

06
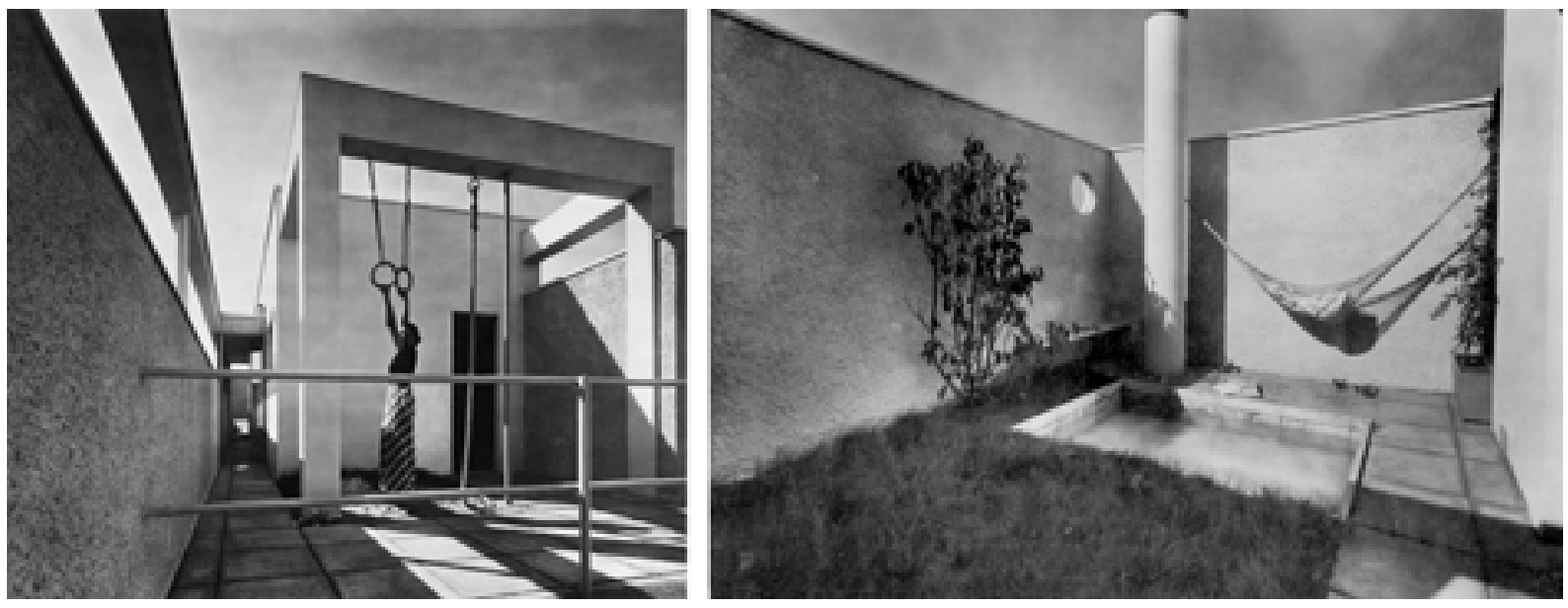

07 
pal, a NE, la sala se abre al jardín a través de una gran corredera metálica oscura, que se recoge en el interior de la pared. Interior y exterior se funden, espacial, climática, visual y funcionalmente. La vida transcurre indistintamente en el interior y en el exterior (fig. 06). En una jardinera a ras de suelo, de $55 \times 55 \times 45 \mathrm{~cm}$, construida en el forjado, se recorta frágil, contra los blancos muros, el naranjo: "Un árbol en el bosque, un hilo de agua en el torrente, no se ven, no se distinguen; un árbol verde en la desolación de un claro infinito, un hilo de agua clara en la arena del desierto, pueden conmovernos, hasta hacernos llorar"8. Según presume el arquitecto, con una floración copiosa, y hasta una cuarentena de frutos bien madurados, en el clima rígido de Milán.

En la planta superior, en la terraza abierta sobre el doble espacio, se dispone el gimnasio, cerca del baño y con vistas lejanas, a través de los huecos en fachada, sobre los Alpes. Cuerdas, aros y barras, cuelgan de una viga exterior, prevista para una posible ampliación de la casa. En el suelo, arena, césped, y una jardinera, el resto pavimento (fig. 07). Un paso en la fachada SE nos conduce a la otra terraza, en el extremo opuesto del prisma, que se concibe como un patio ajardinado y en donde las tres fachadas, de 2,60 m de alto, se macizan por completo. Sobre ésta abre el dormitorio del matrimonio a través de un porche, de forma que sólo en invierno entra el sol oblicuo de mediodía, más bajo sobre el horizonte. Aquí se disponen un plano de arena, en el que tomar baños de sol, protegido de las vistas y del viento, un estanque, y una superficie importante de césped, sobre 20 cm de tierra, donde se siembran plantas de flor-zinnias, anémonas-y se planta el cerezo "totalmente cubierto de flores en primavera", protagonista de la mayoría de fotografias de la casa. El agua de lluvia se recoge en la cisterna de mármol al aire libre, "un agua-muerta, que por su temperaturaambiente y su composición, es más indicada para el riego que el agua potable" ${ }^{\prime \prime}$. Una chimenea de tubo circular, pintada de color rosa, recoge los vapores y el hollín de la cocina y la caldera, y los conduce lejos, por encima del espacio habitable, porque "urge eliminar en la medida de lo posible, los inconvenientes del humo y de los vapores; $y$ dar al complejo chimeneavapores un aspecto menos descuidado y antiestético, evitando también el desorden característico en el que deriva generalmente"".

EL REGISTRO DE LO COTIDIANO
Luigi Figini recoge, en un archivo cuidadosamente ordenado, cientos de fotografías y dibujos del día a día de los habitantes, no sólo del arquitecto y su esposa, sino también de los árboles, las flores y los pájaros, en las terrazas-jardín. Lejos de eventos más importantes, son las actividades cotidianas las que se muestran en este álbum de fotos y constituyen la memoria arquitectónica de la casa. Muchas de estas imágenes serán utilizadas como base de collages y otros ejercicios artísticos. Su afición a la pintura y a la fotografía -que comparte con su mujer- se convierte en una actividad casi secreta, metódica, y muy personal, que desarrolla a lo largo de casi toda la vida en esta preciosa casa de Milán'2.

Entre estas fotografías, muchas se refieren a la vida de los pájaros en las terrazas-jardín, con las que pensaba compaginar un libro. Para ello había instalado en el porche, junto a su dormitorio, un verdadero observatorio fotográfico, en el que sorprendía a los pájaros que acudian en busca de insectos, del agua del estanque, de los frutos del cerezo. Mirlos, gorriones y petirrojos picoteaban en las zarzas, bebían en el estanque 
o sorbían un trozo de sandía que alguien había olvidado. En esta casa silenciosa, ajena al ruido de la ciudad, el quehacer del pájaro en la hierba, el picoteo en la ventana, la visita agradecida en busca de las migas esparcidas en el patio pasa a ser lo más importante en la vida de sus habitantes.

El arquitecto italiano también anota -en una pequeña libreta de colegio- diferentes reflexiones en referencia a la arquitectura de la casa, que distingue entre "notas estéticas" y "notas prácticas". Entre las primeras, la que contempla la posibilidad de convertir una de las ventanas en un acuario, como si de una naturaleza viviente se tratara; o la disposición en su interior de pequeños y numerosos reflectores para producir "efectos infinitos variables de luz directa e indirecta" hojas se dibujan detallados y sofisticados contenedores de cinc, con mecanismos para su limpieza y transporte, para colocar árboles en la terraza. Y en el baño se disponen pequeñas lámparas para iluminar el agua de la bañera con efectos de "gruta azul". Dándole la vuelta a la libreta encontramos las notas técnicas y prácticas. Aquí se refiere el arquitecto a la casa que crece, para adaptarse a las distintas necesidades de la familia, y a la casa thermos, que pretende controlar el clima a través de sistemas pasivos, llenando por ejemplo "la casa de aire fresco y puro del Norte por la mañana, para después cerrar herméticamente, y no abrir más mientras la T.i. sea inferior a la T.e.", inundando la cubierta de agua "en caso de fortísimo calor" o disponiendo "piletas exteriores en la terraza, a sur para que el agua se caliente al sol, y a norte con una pequeña cascada con peces rojos, plantas acuáticas, musgo y helechos"14.

Gegé Bottinelli es la protagonista de los cuadros vivientes, en los que la figura femenina se compone junto a elementos naturales y artesanías del Mediterráneo: vasijas de arcilla, estrellas de mar. Se utiliza la fotografía como instrumento rápido para registrar, modificar y superponer imágenes, composiciones efímeras, y todo ello tiene lugar con el fondo de las terrazas de la casa. Giuliano Gresleri ve en las pruebas, realizadas paso a paso, una superación del orden clásico, de las raíces griegas, en la búsqueda de un equilibrio formal a través de montajes dadaístas o puristas ${ }^{15}$.

CONSTRUIRLA ANTICIUDADEN LA CIUDAD
En la memoria de 1935, Figini propone esta casa como una pieza susceptible de ser insertada en un bloque de apartamentos de 10, 25, o incluso 50 plantas, porque "un prisma de cielo y de aire no debería faltarle a nadie: una base de $\mathrm{m}^{2}$ por persona, una altura indefinida, en dirección al cénit" ${ }^{16}$. Se trata de recuperar "el mínimo de las necesidades materiales y espirituales que el hombre debería encontrar satisfechas en su vivienda"1 ${ }^{17}$. Detrás de este proyecto tan representativo de la arquitectura racional italiana está el deseo de Luigi Figini de proporcionar a cada uno, en la casa "anticuartel"18, la posibilidad de reencontrar la individualidad e intimidad perdidas en la metrópolis oscura y ruidosa ${ }^{19}$. Construir la anticiudad en la ciudad: "El hombre ha vivido durante siglos en contacto con la tierra, sus estancias pegadas al suelo, a las flores, a los frutos, a los árboles; sus pies apretando cada día la tierra. Quizás entonces se sintió feliz (o por lo menos, tan feliz como le está concedido de serlo en nuestro mundo). La ciudad lo ha separado de la tierra madre: el hombre se ha vuelto triste y su vida más corta, se renueva el mito de Anteo"20. 


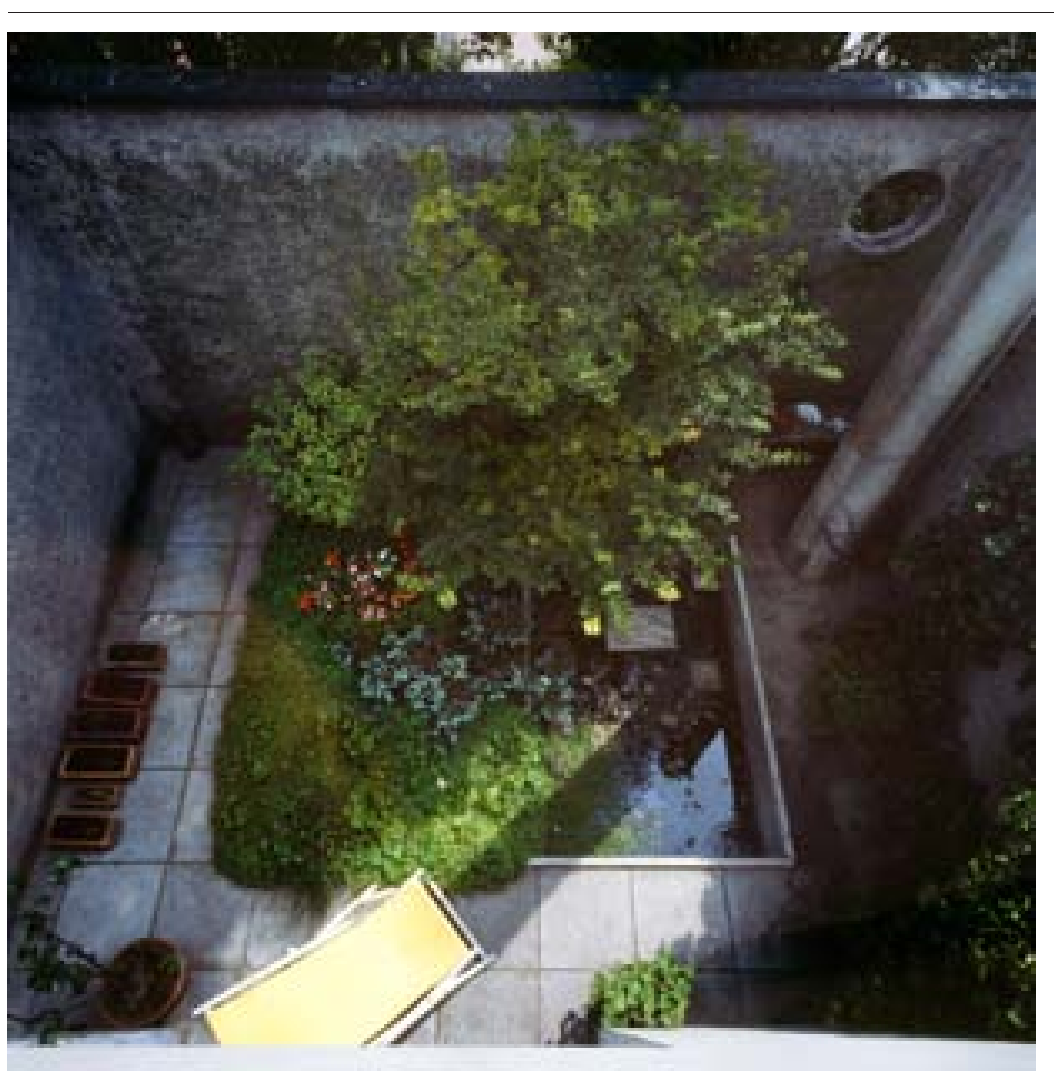

08

En su propuesta de habitar, este beneficioso y necesario contacto con la tierra pasa por "eliminar, purificar, aislar, reducir a porcentajes humanos, a otra escala de proporciones, los términos de la ciudad"21. Es decir, invertir los porcentajes de sol, de cielo y de verde -elementos naturales, los del Creador- respecto los de edificio, polvo, carteles... elementos artificiales, producidos por el hombre.

La terraza-jardín se levanta del suelo, se abre al cielo y se encierra entre muros, para eliminar las distracciones y los "elementos visibles de la civilización mecánica" ${ }^{22}$. Filtrar, diafragmar, con telas, persianas, correderas, las vistas, para "hacer soledad alrededor del sol, del verde, del azul, e introducirlos, solos, aislados en la habitación del hombre" ${ }^{23}$. La operación plástica consiste en recortar, separar y superponer, en un orden inusual, a modo de collage, trozos de sol, de verde y de azul, e introducirlos en la vivienda, entre muros. En el plano horizontal: césped, arena y agua; en el vertical: cielo, nubes y sol. Recortes precisos y geométricos, que cambian con la orientación, con los días y las estaciones (fig. 08). Lejos de la composición por ejes de la casa pompeyana, el autor prefiere la libertad formal de los huertos medievales, de los patios populares, que permite distribuir los espacios verdes, las fuentes y los estanques, más "metafísicamente", por aislamiento, y de un modo abstracto, con relación a la orientación, a las visuales, a los usos y circulaciones. Sin un orden geométrico impuesto, para servir al hombre, para que éste pueda reencontrar, en lo infinitamente pequeño, un reflejo del sueño infinitamente grande, soñado a lo largo de siglos de existencia.
Fig. 08

La terraza jardín en la segunda planta. 
El autor se refiere a las pinturas de Rousseau "Yadwigha", o de De Chirico, "Interior" y "Interior en un valle". Un diván en la selva tropical; sillas, mesas y columnas en el paisaje abierto; un árbol, el mar, en una estancia. Escenas cotidianas llenas de serenidad en las que interior y exterior conviven. "Nunca como hoy el hombre se ha sentido tan seco y solo, prisionero de la cárcel que ha construido con sus propias manos (esta cárcel se llama casa, esta cárcel se llama ciudad). Y nunca como hoy el hombre ha sentido fuerte esta ansia de evadirse hacia el reino de los árboles, hoy que un mundo vegetal perdido, con dulce violencia, se redirige para pasar a formar parte de los elementos domésticos de su vida cotidiana" ${ }^{24}$.

Con el paso de los años el escenario cambia, porque "una terraza-jardín no es una naturaleza muerta abstracta, no es sólo una perspectiva arquitectónica de yeso, de cemento, de mármol. Es un complejo vivo, vegetante, en continuo devenir y transformarse" ${ }^{25}$. A la trama geométrica, clásica, inventada por el hombre, se le superpone, romántico, "el arabesco que la naturaleza teje cada estación"26. Las leyes de la naturaleza entran en la casa, se instalan cerca del día a día del hombre, que las había olvidado, y ofrecen nuevas posibilidades de vida para el cuerpo: salud, deporte, y para el espíritu: clima, abstracción (fig. 9).

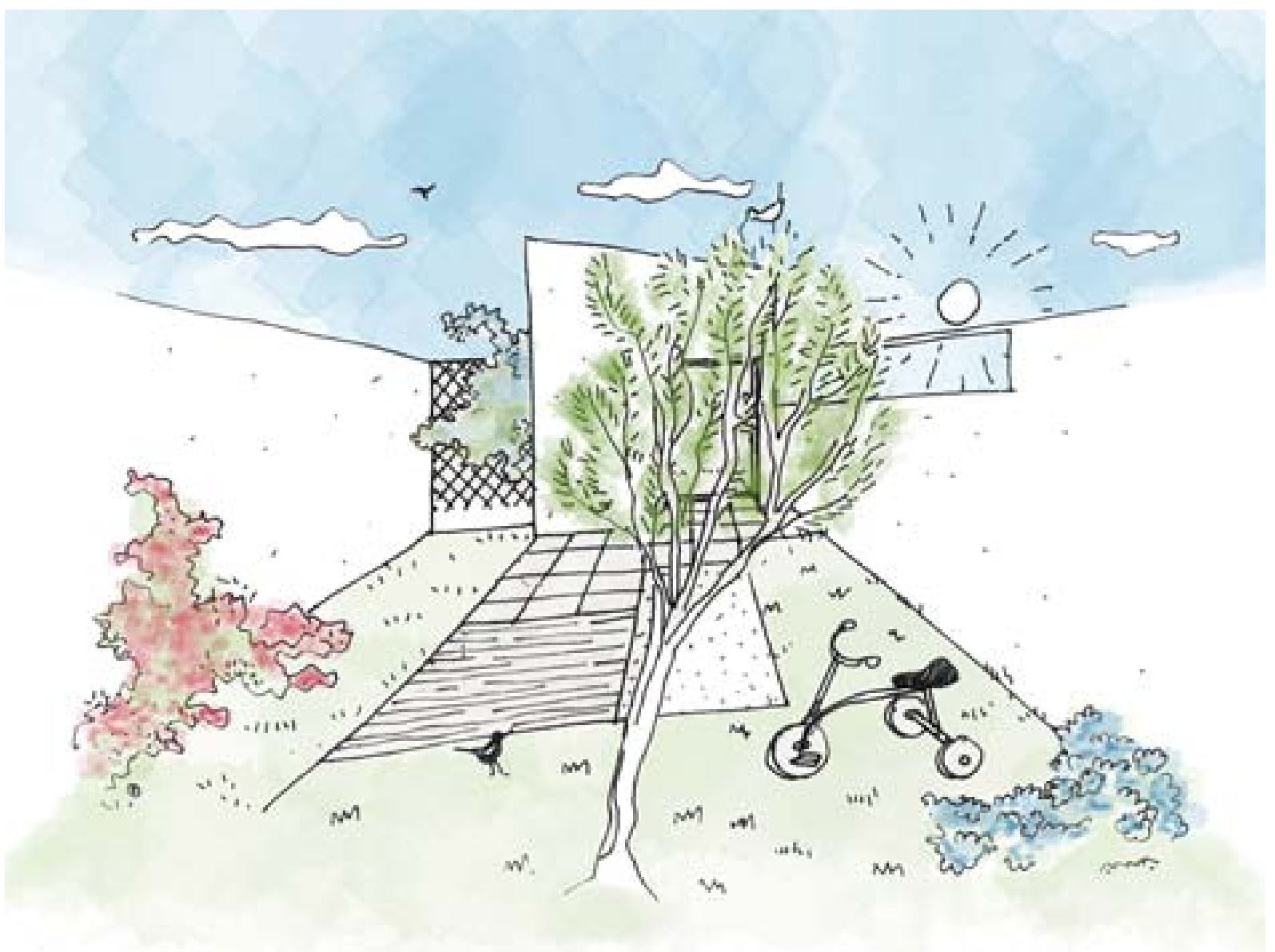


Fig. 09

Recortes de verde, agua, y cielo.

Fig. 10

Vista aérea de la Villa Figini.
RECUERDOS EN BLANCO SOBRE FONDO NEGRO
En la introducción que el arquitecto escribe en el libro encontramos el motivo de esta comunión casi mística con el aire, el sol y el verde. Se trata de un motivo muy personal el que acompaña esta propuesta y no es otro que un tributo del arquitecto a la memoria de su padre. En este texto reconoce Figini la importancia de los recuerdos, que quedan grabados en nuestro interior con la nitidez de la tiza blanca sobre el fondo negro, como de pizarra. Ahí permanecen, para retornar, como marcas claras e imborrables, de una vida anterior, "horas y días, cosas y grupos de cosas, obsesiones, climas absurdos y atmósferas ficticias, fábulas privadas y mitologías personales, cándidas en la amplificación de una fantasía, aún no corrompida"27. Herméticos e indiferentes para los demás, afloran después de unos años de una forma imprevisible para indicar un camino, una dirección en el pensamiento o en la vida misma.

Recuerdos como los de su infancia en la azotea de la casa familiar en Milán, donde su padre había acondicionado un jardín colgante, en el que había sembrado en cajas y barreños toda una serie de plantas trepadoras, árboles frutales y arbustos de flor. Como en un pequeño huerto campestre crecían manzanos, cerezos, caquis, groselleros y parras, que daban sombra entre las anillas, cuerdas y barras dispuestas para la gimnasia matutina. Es especialmente atractivo el párrafo en el que el arquitecto describe las jornadas en su "terrazareino de la vieja ciudad: encima de un vacilante triciclo de hierro en el que inspeccionaba de un lado a otro el limitado territorio. En los días más calurosos mi madre llenaba con el agua de una fuente -usada para regar las plantas- la gran tina de cinc: el sol la calentaba para nuestro baño de la tarde. Algunas horas más tarde, con la comida al fresco, en la terraza verde, se acababa mi jornada"28. Era este edificio neoliberty el único entonces con azotea entre los tejados oscuros de las casas vecinas, del mismo modo que se encuentra ahora su casa, 80 años más tarde, entre edificios extraños al sol, al cielo, al verde (fig. 10). 


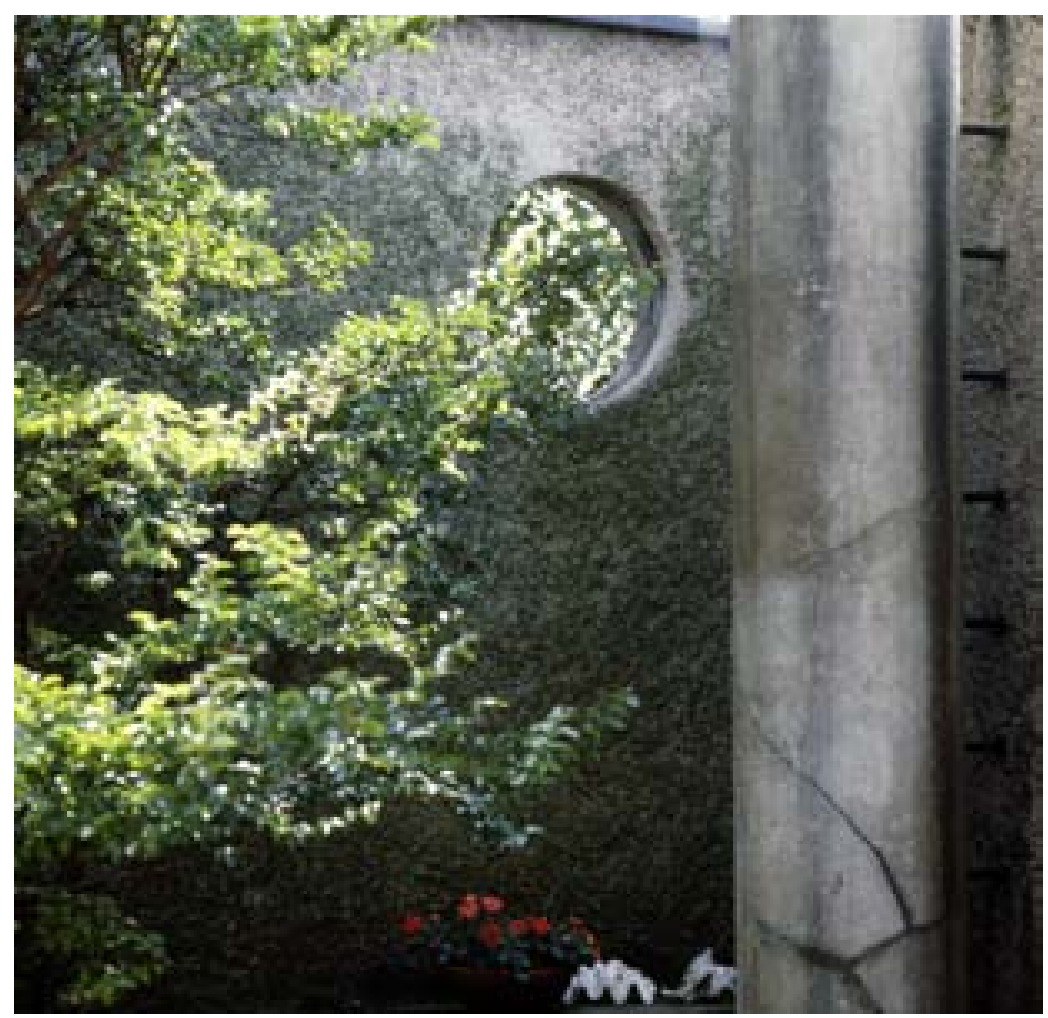

11

Construir la casa propia significó para este arquitecto reencontrar el Paraíso perdido, ya que "en los años que siguieron después, todo cambió. Casas oscuras y sombrías, habitaciones a Norte sin sol y sin terraza me acogieron, después. En el horizonte de mi exilio no había más que vistas de patios tétricos, donde mujeres despeinadas sacudían alfombras por la mañana, tendían paños a secar por la tarde: no florecían en el balcón ni geranios ni adelfas, sólo había cajas, mosquiteras, pollos muertos y muros grises de hormigón, y sobre todo esto, mucha tristeza y mucho fastidio. El exilio en el país de los hombres" ${ }^{29}$. En su casa el arquitecto reconstruye el mundo precioso, íntimo, de su infancia, en el que los actos cotidianos -los del niño de entonces, los del hombre-arquitecto-pintor de ahora- se tornan casi sagrados, nítidos e inmaculados. La infancia del hombre, la infancia de los tiempos, reencontrada.

De las primeras imágenes -en las que un escuálido árbol se recortaba contra el blanco muro- las terrazas se convirtieron, con el tiempo y los cuidados, en agradables jardines colgantes, frescos y floridos, porque "los esfuerzos de plantación y mantenimiento, a lo largo del tiempo y por tiempo, encuentran una compensación adecuada" ${ }^{30}$. El cerezo crece y florece, y el arquitecto lo muestra, orgulloso, en una serie de fotografías tomadas a lo largo de los años (fig. 11).

Católico de rigurosos principios, con una profunda fe franciscana, antijerárquica y deseosa de un regreso a las raíces paleocristianas ${ }^{31}$, el arquitecto deja finalmente que la naturaleza invada los patios y así lo afirma en la vejez: "Yo mismo he deseado rodearme de un bosque. En el fondo ha sido para mí casi un rito de expiación. Tantos arquitectos, geómetras e ingenieros han últimamente, con su arquitectura, aplastado 
la naturaleza. Yo por el contrario he dejado (o mejor he querido) que la naturaleza dominase mi arquitectura. Pero yo no lo llamo exactamente dominio, sino afectuoso dominio o mejor aún, afectuoso abrazo" ${ }^{32}$. Quizás acabase viendo en las plantas que invadían su casa, en los pájaros que le visitaban con frecuencia, la mano del Creador.

Este abrazo con la naturaleza manifestado por el arquitecto estuvo desde un principio detrás de la construcción de esta obra que fue en su día manifiesto, no sólo de arquitectura, sino también de "una nueva forma de vivir y de actuar colectiva" ${ }^{3}$ (fig. 12). Esta obra -que se ofrecía en su día como prototipo para ser repetida- acaba siendo en el ejercicio de la vida y la actividad artística de su dueño, un lugar sagrado, un templo para el ejercicio diario de la poesía, porque "...el Dios cristiano no prohíbe al hombre el intento ingenuo, ingenioso y desesperado, de reconstruir "de memoria" (como de memoria, el que ama intenta renovar la presencia del amado desaparecido), una imagen provisional, aunque sea pálida, mezquina o infiel, del Paraíso perdido" ${ }^{34}$. RA
Fig. 11

La terraza jardín en la segunda planta.

Fig. 12

Vista de la terraza jardín desde el salón.

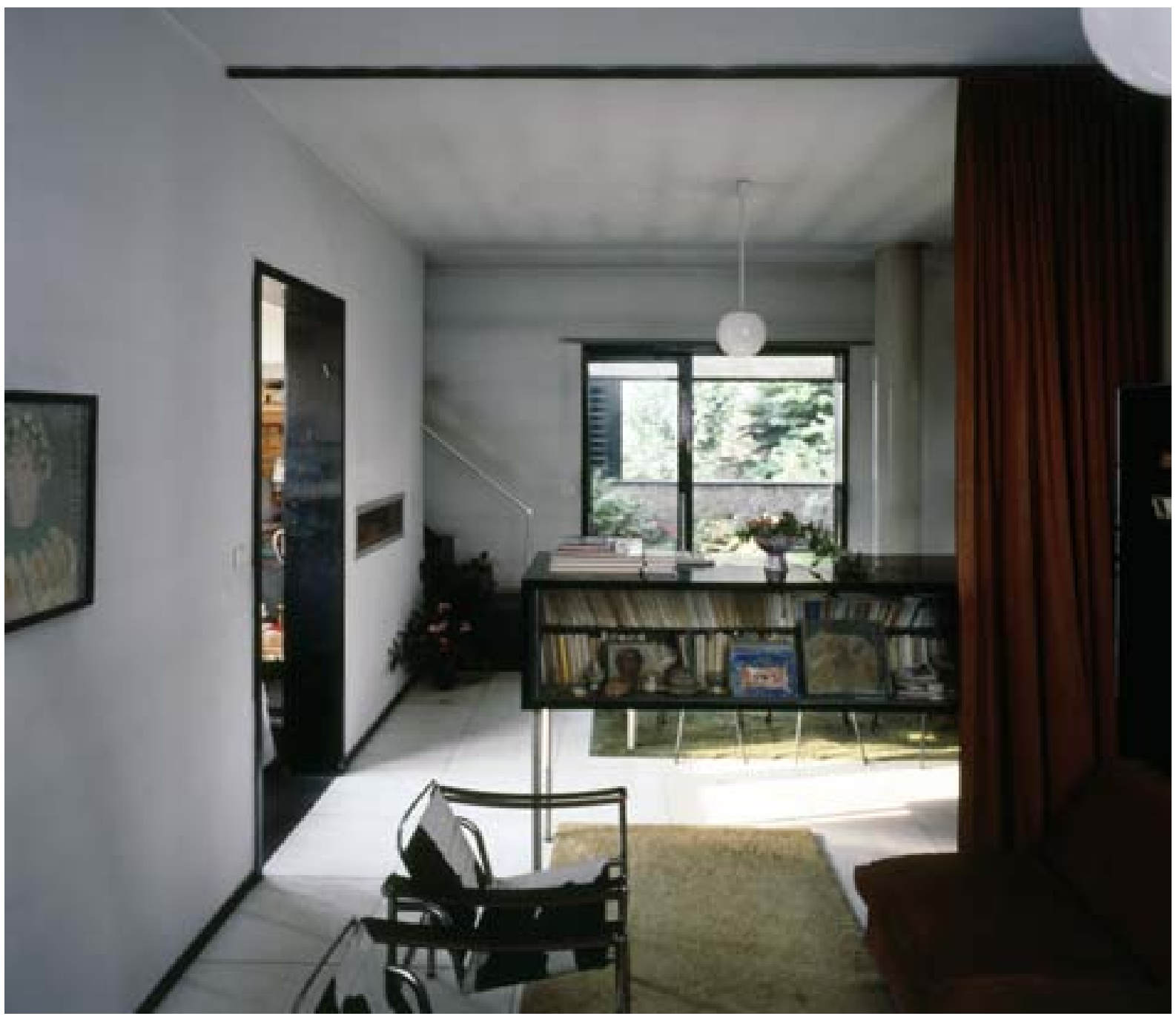




\section{Notas}

01. FIGINI, Luigi, L'elemento verde e l'abitazione, Quaderni di Domus n. 7 Ed. Domus, Milán, 1950, p. 27.

02. Ibid., p. 12

03. Ibid., p. 67

04. Ibid., p. 73

05. GREGOTTI, Vittorio", Un prisma di cielo", A.A.V.V, en Luigi Figini-Gino Pollini. Opera completa, Ed. Electa, Milán, 1996, p. 23.

06. Aunque firme esta obra individualmente, Luigi Figini trabajaba desde 1926 -año en que finaliza sus estudios- con Gino Pollini, y ambos formaban parte del Gruppo 7.

07. F. Melotti era hermano de la mujer de Gino Pollini. Poeta, pintor y escultor, sus obras aparecen en otras obras de los arquitectos milaneses: bar Craja 1930, villaestudio para un artista 1933, o restaurante Campari 1937.

08. FIGINI, Luigi, L'elemento verde e l'abitazione, op.cit., p. 7.

09. Ibid., p. 74.

10. Ibid., p. 77 .

11. Ibid., p. 78.

12. Gegé Bottinelli y Luigi Figini exponen sus fotogramas en al $V$ Trienal de Milan en 1933, junto a ManRay, Hans Arp, Max Ernst, o Moholy-Nagy.

13. Cuaderno manuscrito de Luigi Figini, en: DE CARLI, Margherita, "Lo spazio segreto", Ottagono, 1993, n. 108, p. 63.

14. ACERBONI, Francesca, en POSTIGLIONE, Gennaro (ed), One hundred houses for one hundred european architects of the twentieth century, Ed. Taschen, Colonia, 2004, pp. 124-127.

15. GRESLERI, Giuliano, “Minnesánger, il cantore d'amore. Prime note sul pittore Luigi Figini", A.A.V.V, en Luigi Figini-Gino Pollini. Opera completa, op. cit. pp. 467-482.

16. FIGINI, Luigi, "Appunti per una casa", Quadrante, 1936, n. 33, en SAVI, Vittorio, Figini e Pollini. Architetture 1927-1989, Ed. Electa, Milán, 1990, p. 133.

17. Ibid.

Referencias bibliográficas

18. Ibid.

19. En este caso -como ocurre en otros tantos- la casa que el arquitecto construye para sí mismo es utilizada como ejemplo para repetir a gran escala, para extender a la mayoría. Ver: MARTíNEZ, Anna, La casa del arquitecto, tesis doctoral, Universidad Politécnica Catalunya, 2008.

20. FIGINI, Luigi, L'elemento verde e l'abitazione, op.cit., p. 74.

21. FIGINI, Luigi, "Appunti per una casa”, Quadrante, op.cit., p.133.

22. FIGINI, Luigi, L'elemento verde e l'abitazione, op. cit., p. 73. También Richard Neutra redacta instrucciones parecidas a evitar las visuales sobre elementos mecánicos, en su libro Mystery and Realities of the Site.

23. FIGINI, Luigi, "Appunti per una casa”, Quadrante, 1936, n. 33, en SAVI, Vittorio, op. cit., p. 133.

24. FIGINI, Luigi, L'elemento verde e l'abitazione, op.cit., p. 28.

25. Ibid., p. 79.

26. Ibid., p. 79

27. Ibid., p. 7

28. Ibid., p. 8.

29. Ibid., p. 8.

30. Ibid., p. 79 .

31. POLIN, Giacomo, "Five memos for Figini \& Pollini”, AA. VV., en Luigi Figini-Gino Pollini, Opera completa, op. cit., p. 169.

32. Case che duran. "L'abitazione di un architetto, 1935", Abitare, 1978, n. 167, p. 39. Reflexiones parecidas las encontramos en la experiencia del habitar y la relación con el jardín en la casa de Tacubaya, de Luis Barragán. Ver MARTíNEZ, Anna, La casa del arquitecto, tesis doctoral, Universidad Politécnica Catalunya, 2008.

33. FIGINI, L., "Appunti per una casa", op. cit., p. 133.

34. FIGINI, Luigi, L'elemento verde e l'abitazione, op. cit., p. 8.

\section{-A.A.V.V, Luigi Figini-Gino Pollini, Opera} completa, Ed. Electa, Milán, 1996.

- Case che durano, "L'abitazione di un architetto, 1935”, Abitare, 1978, n. 167, pp. 32-39.

- DE CARLI, Margherita, "Lo spazio segreto", Ottagono, 1993, n. 108, pp. 57-64.

- FIGINI, Luigi, L'elemento verde e l'abitazione, Quaderni di Domus n. 7, Ed. Domus, Milán, 1950.

- MARTINEZ, Anna, La casa del arquitecto, tesis doctoral inédita, Departamento Proyectos Arquitectónicos, Universidad Politécnica Catalunya, 2008, http://www. tesisenred.net/handle/10803/53596.

- POLIN, Giacomo, "Gli Interni di Figin e Pollini como paesaggio artificiale", Rassegna IX, 1987, n. 3, pp. 20-21.

- POSTIGLIONE, Gennaro (ed), One hundred houses for one hundred european Architects of the twentieth century, Ed.Taschen, Colonia, 2004.

- RYKWERT, Joseph, "Figini and Pollini", Architectural Design AD. 1967, Vol 37, n. 7, pp. 369-378.

- SAVI, Vittorio, Figini e Pollini. Architetture 1927-1989, Ed. Electa, Milán, 1990.

- THERMES, Laura, "Una nota sulla casa di Luigi Figini", in Memoria. "La casa di Luigi Figini al Villagio dei Giornalisti", Controspazio IX, 1977, n. 1, pp. 34-39.

\section{AGRADECIMIENTOS}

Este artículo se ha redactado gracias al apoyo de la Secretaria Universitats i Recerca, Departament Empresa i Coneixement, Generalitat de Catalunya, en el marco del programa de Doctorado Industrial. 
